\title{
AnÁlises de Fluorescência e Consumo de ÁGUA EM Brachiaria decumbens após APLICAÇÃo de Herbicidas EM Pós-EMERgênCIA
}

\author{
Analysis of Fluorescence and Water Consumption in Brachiaria decumbens after Herbicide \\ Application in Post-Emergence
}

ARALDI, R. ${ }^{2}$, GIROTTO, M. ${ }^{2}$, VELINI, E.D. ${ }^{3}$, TROPALDI, L. ${ }^{2}$, SILVA, I.P.F. ${ }^{2}$ e CARBONARI, C.A. ${ }^{3}$

\begin{abstract}
RESUMO - A análise da fluorescência da clorofila vem sendo largamente utilizada no entendimento dos mecanismos da fotossintese propriamente dito, bem como na avaliação da capacidade fotossintética alterada com a aplicação de herbicidas. O consumo de água pelas plantas é uma maneira também de avaliar a atuação dos herbicidas nas plantas daninhas. O objetivo deste trabalho foi avaliar a fluorescência através da taxa de transporte de elétrons, consumo de água e fitointoxicação de Brachiaria decumbens após aplicação de quatro herbicidas de diferentes mecanismos de ação. Aos 30 dias após a semeadura de $B$. decumbens, as plantas foram arrancadas dos tubetes e preparadas para os tratamentos. Elas tiveram o sistema radicular colocado em tubos falcon preenchidos com água, e a superficie dos falcon foi isolada com papel-alumínio, para evitar evaporação do sistema. Os herbicidas aplicados foram: glyphosate, haloxyfop-methyl, diuron e amicarbazone. A aplicação foi feita com um pulverizador estacionário instalado em laboratório; após a aplicação dos tratamentos, as plantas foram mantidas em casa de vegetação. Foi avaliada a taxa de transporte de elétrons (ETR), o consumo de água e a fitointoxicação das plantas em vários periodos após o início do experimento. Os dados de ETR e fitointoxicação foram expressos em porcentagem da testemunha e submetidos à análise de variância e à comparação das médias. Para o consumo de água, os dados foram acumulados e ajustados por modelos de regressão. Assim, pode-se dizer que as plantas de $B$. decumbens tiveram respostas diferentes aos herbicidas aplicados, e o consumo de água das plantas está relacionado diretamente com o transporte de elétrons. A metodologia fundamentada no fluorômetro mostrou-se adequada para verificar a intoxicação antecipada em $B$. decumbens submetidas ao amicarbazone e diuron antes mesmo da verificação visual de intoxicação.
\end{abstract}

Palavras-chave: fluorômetro, glyphosate, haloxyfop-methyl, diuron, amicarbazone.

\begin{abstract}
Analysis of chlorophyll fluorescence has been widely used in the attempt to understand the mechanisms of photosynthesis itself, and to evaluate the changes in photosynthetic capacity, with herbicide application. Water consumption by plants is also a form of evaluating the action of herbicides on weeds. The objective of this study was to evaluate fluorescence through electron transport rate, water consumption, and phytotoxicity on Brachiaria decumbens after application of four herbicides, based on different mechanisms of action. B. decumbens plants were removed from the tubes at 30 days after seeding and prepared for the treatments. Their roots were placed in falcon tubes filled with water, and their surfaces were insulated with aluminum paper to avoid water evaporation from the system. The herbicides used were: glyphosate, haloxyfop-methyl, diuron, and amicarbazone. Treatments were applied using a stationary sprayer installed in the laboratory, and the plants were kept under greenhouse conditions, after application. Electron transport rate (ETR), water consumption and plant phytotoxicity were evaluated at various periods after the start of the experiment. ETR and phytotoxicity data were expressed as percentage of control and subjected to analysis of variance and comparison of means. The water consumption data were accumulated and adjusted for regression models. The plants of $\boldsymbol{B}$. decumbens had different responses to the
\end{abstract}

Recebido para publicação em 31.3.2011 e aprovado em 17.5.2011.

2 Pós-Graduação em Agronomia pela Faculdade de Ciências Agronômicas - FCA/UNESP, Campus de Botucatu, Fazenda Experimental Lageado, Caixa Postal 237, 18603-970 Botucatu-SP, <araldi@fca.unesp.br>; ${ }^{3}$ Professores, Eng ${ }^{\circ}$ Agr ${ }^{\circ}$, Doutores, Dep. de Agricultura, FCA/UNESP, Campus de Botucatu.

Planta Daninha, Viçosa-MG, v. 29, p. 1053-1060, 2011. Número Especial 
herbicides applied and water consumption by the plants is directly related to electron transport. The methodology based on fluorometer proved to be adequate to verify early intoxication in B. decumbens submitted to amicarbazone and diuron, even before the visual determination of intoxication.

Keywords: fluorometer, glyphosate, haloxyfop-methyl, diuron, amicarbazone.

\section{INTRODUÇÃO}

As plantas daninhas reduzem o crescimento e o desenvolvimento das culturas de interesse comercial, sendo a interferência causada por essas plantas um dos fatores críticos no processo produtivo (Kuva et al., 2000). Em razão dessa grande competitividade exercida pelas plantas daninhas, vários estudos têm sido realizados com o objetivo de entender o comportamento das espécies daninhas e, consequentemente, manejá-las de forma satisfatória.

Atualmente, entre as plantas daninhas mais problemáticas para a agricultura, destacase Brachiaria decumbens, popularmente conhecida como capim-braquiária, que é originária da África e tem sido amplamente disseminada pelas regiões tropicais do mundo, devido às suas qualidades como forrageira. Ela destaca-se por apresentar excelente adaptação a solos de baixa fertilidade, fácil estabelecimento e considerável produção de biomassa durante o ano, proporcionando excelente cobertura vegetal para o solo (Alvim et al., 1989).

Para o controle químico de $B$. decumbens, existe atualmente um grande número de produtos recomendados para aplicação em préemergência. Muitos deles podem ser aplicados também em pós-emergência inicial, dependendo do estádio de desenvolvimento das espécies a serem controladas.

O glyphosate é um herbicida que se destaca por exercer efetivo controle sobre um grande número de espécies daninhas (Toledo et al., 2003). Trata-se de um herbicida sistêmico, não seletivo e altamente solúvel em água; seu mecanismo de ação baseia-se na interrupção da rota do ácido chiquímico, responsável pela produção dos aminoácidos aromáticos fenilalanina, tirosina e triptofano, essenciais para a sintese proteica e divisão celular em regiões meristemáticas da planta (Cole et al., 1983).
Em um ensaio realizado com aplicação de glyphosate em $B$. decumbens sob solução nutritiva, observou-se, aos 15 dias após a aplicação, controle acima de $95 \%$ nas plantas, que apresentaram raízes com coloração amarronzada, indicando a necrose de tecidos (Tuffi Santos et al., 2005).

Já o haloxyfop-methyl é utilizado como pósemergente primariamente para o controle de gramineas em culturas de folhas largas e possui alto grau de seletividade, com pouca ou nenhuma atividade nessas folhas; é absorvido pelas folhas e translocado no floema para regiões meristemáticas. Esse herbicida inibe a sintese de lipídios e, consequentemente, a produção de membranas celulares, paralisando o crescimento da planta (Stephenson et al., 2006). Os sintomas de injúria causados por esses herbicidas não são evidentes até vários dias depois do tratamento, embora as plantas cessem o crescimento logo após a aplicação do herbicida.

O diuron e o amicarbazone inibem a transferência de elétrons no fotossistema II, a qual, segundo Fuerst \& Norman (1991), impede a redução da quinona $A$, por esta competir com a quinona $\mathrm{B}$ pelo sítio de ligação à proteína $\mathrm{D}_{1}$, o que ocasiona a saída de $Q_{B}$ e, consequentemente, interrupção no fluxo de elétrons, não permitindo com isso a redução do $\mathrm{NADPH}$, a qual é essencial para a fixação de $\mathrm{CO}_{2}$ (Breitenbach et al., 2001).

Em relação à fase de transporte de elétrons durante a fotossintese nas plantas, temse que a luz é absorvida por pigmentos do complexo antena, que, ao excitarem os elétrons, transferem energia para os centros de reação dos fotossistemas II e I (Young \& Frank, 1996). Quando ocorre excesso de energia, esta pode ser dissipada na forma de fluorescência (Krause \& Winter, 1996). Portanto, uma das formas de monitoramento da inibição ou redução na transferência de elétrons entre os 
fotossistemas de plantas sob aplicação de herbicida, que pode ser observada ainda em folhas intactas, é a fluorescência da clorofila (Maxwell $\&$ Johnson, 2000), em que a redução na dissipação da energia pelo processo fotoquímico é refletida por incremento correspondente na fluorescência.

A análise da fluorescência da clorofila vem sendo largamente utilizada no entendimento dos mecanismos da fotossintese propriamente dita, bem como na avaliação da capacidade fotossintética alterada com a aplicação de herbicidas (Ireland et al., 1986). Para esse tipo de avaliação são utilizados fluorômetros em aplicações que variam desde a rápida identificação de injúrias causadas ao aparelho fotossintético, mesmo quando o sintoma ainda não é visível, até a análise detalhada da alteração da capacidade fotossintética da planta.

O consumo de água pelas plantas é uma maneira também de avaliar a atuação dos herbicidas nas plantas daninhas, visto que a eficiência do uso da água pelas plantas está diretamente relacionada ao tempo de abertura estomática, que depende de uma série de fatores, como radiação solar, nível de $\mathrm{CO}_{2}$ no mesofilo, umidade relativa, potencial hídrico e outros de menor magnitude, como vento, substâncias exógenas e ritmos endógenos próprios de cada espécie (Brodribb \& Holbrook, 2003). Dessa forma, a ação de herbicidas em plantas daninhas pode reduzir a condutância estomática e, consequentemente, diminuir o consumo de água pelas plantas, levando-as à morte.

Esta pesquisa teve como objetivo avaliar a eficiência fotossintética através da taxa de transporte de elétrons, o consumo de água e a fitointoxicação de $B$. decumbens após aplicação de quatro herbicidas de diferentes mecanismos de ação.

\section{MATERIAL E MÉTODOS}

O experimento foi realizado em casa de vegetação. Foram utilizados tubetes preenchidos com substrato para a semeadura de B. decumbens. Após 30 dias da semeadura, fase anterior ao perfilhamento, as plantas foram arrancadas dos tubetes e preparadas para os tratamentos, sendo removido das raízes, de forma cuidadosa, todo o substrato presente, evitando possiveis ferimentos no sistema radicular.

Em seguida, as plantas foram colocadas em tubos falcon preenchidos com água ( $45 \mathrm{~mL}$ de água por tubo), os quais tiveram a superficie isolada com papel-aluminio, para evitar evaporação no sistema, garantindo que a única forma de consumo de água fosse através da transpiração das plantas. Foi mantido um frasco com água e papel-alumínio, para aferir a eficiência do método e evitar a evaporação de água. $\mathrm{O}$ consumo de água foi mensurado pela pesagem de cada um dos recipientes. Os tubos falcon com as plantas em água ficaram em repouso por 24 horas, visando ao seu restabelecimento, em seguida, foram aplicados os diferentes herbicidas na parte aérea.

O ensaio foi constituído de cinco tratamentos, sendo a testemunha e a aplicação de quatro herbicidas: glyphosate, haloxyfopmethyl, diuron e amicarbazone, nas dosagens respectivas de $5,0 \mathrm{~L} \mathrm{ha}^{-1}, 0,45 \mathrm{~L} \mathrm{ha}^{-1}, 3,0 \mathrm{~kg} \mathrm{ha}^{-1}$ e $1,5 \mathrm{~kg} \mathrm{ha}^{-1}$. O experimento foi instalado em delineamento inteiramente casualizado, com seis repetições.

A aplicação do herbicida foi feita através de um pulverizador estacionário instalado em laboratório e munido de uma barra contendo quatro pontas do tipo XR11002. A pulverização foi realizada sob pressão constante de 1,5 bar, pressurizado por ar comprimido, com consumo de calda de $200 \mathrm{~L} \mathrm{ha}^{-1}$. A temperatura no momento da aplicação era de $25^{\circ} \mathrm{C}$, e a umidade relativa, de $70 \%$.

Após a aplicação dos tratamentos, as plantas foram transportadas para casa de vegetação, onde ficaram até o término do ensaio. As avaliações realizadas no experimento foram: taxa de transporte de elétrons, consumo de água e fitointoxicação das plantas.

O consumo de água foi verificado por meio de pesagem no primeiro dia após aplicação e, posteriormente, em intervalos de dois dias. A fitointoxicação foi avaliada aos 7, 14 e 21 dias após aplicação.

Foi registrada a fluorescência, através da leitura da taxa de transporte de elétrons (ETR) com um fluorômetro portátil em vários períodos após o início do experimento, nos intervalos de $1,24,72,120,168,216,264,312,384,432$, 
480 e 528 horas após a aplicação dos herbicidas. As leituras foram feitas na porção mediana das folhas de $B$. decumbens.

A fonte de luz diodo utilizada para medir a fluorescência no aparelho Multi-Mode Chlorophyll Fluorometer OS5p (Opti-Sciences) tem pico de luz vermelha no comprimento de onda de $660 \mathrm{~nm}$, sendo bloqueadas radiações maiores que $690 \mathrm{~nm}$. A intensidade média da luz foi ajustada para o intervalo de 0 a $1 \mu \mathrm{Mol} \mathrm{m} \mathrm{m}^{-2} \mathrm{~s}^{-1}$, com o uso da lâmpada halogênica $35 \mathrm{~W}$. O feixe de luz foi opticamente monitorado no interior da câmara para corrigir as variações devidas mudanças na temperatura do ambiente no aparelho. Os sinais ópticos foram transferidos para a superficie da folha por uma trifurcação personalizada de fibra óptica, sendo de $2,0 \mathrm{~cm}^{2}$ a área iluminada. A luz reemitida foi conduzida via fibra óptica para o aparelho através de três conectores ligados à lateral do OS5p. As análises foram feitas seguindo a metodologia de Genty et al. (1989), avaliando a emissão da fluorescência da clorofila na superficie superior das folhas.

Na iluminação e detecção da fluorescência da clorofila das amostras de $B$. decumbens foi utilizado o protocolo Yield, para mensuração da taxa de transporte de elétrons. Esse protocolo é otimizado para um estado da fotossintese adaptado à luz porque registra as medidas de quantum efetivo produzido no fotossistema II (PSII). Tanto a fonte de luz do sol quanto a luz artificial podem ser usadas para dirigir a fotossintese.

A taxa de transporte de elétrons (ETR) $\mu$ Mols elétrons $\mathrm{m}^{-2} \mathbf{s}^{-1}=(\mathrm{Y})$. $(\mathrm{PAR}) \cdot(0,84) \cdot(0,5)$ é equivalente a: (produção de quantum do PSII) $\mathrm{x}$ (medidas da radiação fotossinteticamente ativa, em $\mu$ Mols elétrons $\mathrm{m}^{-2} \mathrm{~s}^{-1}$ ) $\mathrm{x}$ (coeficiente de absorção da folha) $\mathrm{x}$ (fração de luz absorvida pelo complexo antena do PSII). O ETR é uma medida da separação de cargas do centro de reação do PSII. Na equação são usados valorespadrão, porém, ambos os coeficientes de absorção e fração da luz absorvida pelo PSII podem ser trocados. Embora 0,84 seja um valor médio para muitas espécies de plantas, trabalhos têm mostrado que o coeficiente de absorção da folha pode variar com a qualidade da luz, a espécie, o conteúdo de clorofila e a refletância da folha. Quanto à fração de luz que é absorvida pelo complexo antena do PSII, os trabalhos mostram que ocorre variação de acordo com a espécie, que se estende de 0,42 a 0,60 (Laisk \& Loreto, 1996).

Como o parâmetro ETR determina a taxa de transporte de elétrons fotossintético no PSII, o uso do valor do ETR permite detectar o efeito da atuação do herbicida em nível de concentração de 0,5 micromoles $\mathrm{dm}^{-3}$, enquanto o método tradicional, que inclui a medição do parâmetro $\mathrm{Fv} / \mathrm{Fm}$, permite detectar apenas em um nivel de concentração que é 100 vezes maior (Korres et al., 2003; Abbaspoor et al., 2006), justificando o uso da metodologia empregada.

Após o término de experimento, foi quantificada a massa seca das folhas. Para isso, foi utilizada uma câmara de circulação forçada com $44^{\circ} \mathrm{C}$, por um período de sete dias. Por meio da massa seca de uma área conhecida, foi possivel estimar a área foliar das plantas com os valores de massa seca conhecidos, o que possibilitou a padronização do consumo de água das plantas, $\mathrm{em} \mathrm{cm}^{3} \mathrm{~cm}^{-2}$.

Os dados de eficiência fotossintética foram expressos em porcentagem da testemunha e submetidos à análise de variância pelo teste F a 5\% de probabilidade, e a comparação das médias foi feita pelo teste t a $10 \%$ de probabilidade. Os valores para DMS foram representados no gráfico. Os dados de fitointoxicação também passaram por essas análises.

Já os dados de consumo de água foram expressos de forma acumulada, em $\mathrm{cm}^{3} \mathrm{~cm}^{-2}$. Os dados de consumo de água obtidos no ensaio para glyphosate e haloxyfop-methyl foram usados na análise de regressão, utilizando modelo de Mitscherlich $\mathrm{Y}=\mathrm{a} *(1-10-\mathrm{c} *(\mathrm{~b}+\mathrm{x}))$, em que $Y$ é o consumo de água da planta em $\mathrm{cm}^{3} \mathrm{~cm}^{-2}$; e $a, b$ e $c$ são parâmetros da equação, sendo a quantidade máxima do consumo de água da planta; $b$, o deslocamento lateral da curva (estabelecido em 0 , por não considerar o consumo de água no momento 0 ); $c$, a concavidade da curva, o que indica o eficiência do herbicida; e $x$ corresponde ao tempo em dias. Quanto aos dados obtidos para testemunha, diuron e amicarbazone, foi utilizada a análise de regressão simples, usando o modelo $\mathrm{Y}=$ $\mathrm{a}+\mathrm{bx}$, em que $a$ e $b$ são intercepto e coeficiente linear (passando pelo ponto 0 ), respectivamente. 


\section{RESULTADOS E DISCUSSÃO}

Encontram-se na Figura 1 as curvas e dados que descrevem o comportamento do ETR para $B$. decumbens após aplicação de haloxyfopmethyl, glyphosate, diuron e amicarbazone em pós-emergência.

O amicarbazone foi o herbicida que apresentou mais rapidamente a inibição do transporte de elétrons. Apenas uma hora após a aplicação, ocorreu a redução de $40 \%$ do transporte de elétrons, representada pelo valor de ETR. Essa rapidez na redução do ETR possivelmente esteja relacionada com a absorção e translocação mais rápida do herbicida até o sítio de ligação no fotossistema II das plantas, quando comparado com o diuron - herbicida de mesmo mecanismo de ação. Às 24 horas após a aplicação obteve-se redução superior a 90\% do ETR, a qual se manteve com valores baixos até o período de 240 horas após a aplicação. Posteriormente a esse periodo houve recuperação do transporte de elétrons e, 480 horas depois, o valor de ETR já era $70 \%$ superior ao da testemunha.

O herbicida diuron apresentou comportamento parecido com o do amicarbazone, visto que reduziu o transporte de elétrons e, após um periodo de tempo, recuperou novamente esse processo inicial da fotossintese. Uma hora após a aplicação do diuron houve redução de $7 \%$ do ETR. Reduções de 50 e $75 \%$ do ETR em relação à testemunha foram observadas 24 e 72 horas após a aplicação do herbicida, respectivamente. Às 120 horas após a aplicação foi alcançada a inibição do ETR, que se manteve até 216 horas, a partir da qual começou a recuperação. Às 480 horas após aplicação as plantas estavam praticamente normais, pois o transporte de elétrons funcionava com apenas $10 \%$ de redução dos valores de ETR em relação à testemunha.

Essa redução rápida do ETR nas primeiras avaliações do experimento está relacionada com o fato de ambos os herbicidas pertencerem ao mecanismo de ação que inibe o transporte de elétrons no fotossistema II (Fuerst \& Norman, 1991), justamente onde o fluorômetro detecta os valores de ETR. Em trabalho desenvolvido por Dayan et al. (2009), foi monitorado o ETR em plantas de Digitaria sanguinalis e Abutilon theophrasti, quando submetidas à aplicação de amicarbazone e atrazine. A taxa de transporte de elétrons para ambas as espécies foi completamente inibida oito horas após a aplicação dos herbicidas.

Para o herbicida glyphosate ocorreu redução de 5\% do ETR uma hora após aplicação. Às 24 e 72 horas após a aplicação, a redução foi de 40 e $66 \%$, respectivamente. Uma redução de $85 \%$ foi alcançada 120 horas após aplicação, e a inibição se deu com 168 horas.

Com a aplicação do haloxyfop-methyl em $B$. decumbens, as plantas apresentaram pleno funcionamento, com $100 \%$ do ETR da testemunha em até 24 horas depois da aplicação; contudo, a partir de 72 horas a redução do ETR foi de 42\%. No intervalo de 120 a 312 horas, o ETR manteve-se na faixa de $50 \%$ de redução. Às 318 horas após aplicação a redução do ETR passou a 65\%, e com 432 horas as plantas apresentaram a completa inibição do transporte de elétrons.

Para o glyphosate e haloxyfop-methyl, foi mais lenta a redução do transporte nas avaliações iniciais, visto se tratar de mecanismo de ação diferente dos inibidores do fotossistema II. O glyphosate inibe a sintese dos aminoácidos aromáticos (Cole et al., 1983) e o haloxyfop-methyl, a sintese de lipídios, cessando indiretamente o transporte de elétrons nas plantas tratadas. No entanto, esses tratamentos apresentaram lenta inibição do transporte de elétrons na fase inicial, mas que foi fundamental para a morte da planta, diferentemente dos tratamentos com amicarbazone e diuron, em que as plantas recuperaram o transporte de elétrons.

Na Figura 2 encontram-se os dados ajustados pelos modelos de Mitscherlich e linear para o consumo de água acumulado, nos diferentes períodos de avaliação do experimento com aplicação de haloxyfop-methyl, glyphosate, diuron e amicarbazone em pós-emergência para $B$. decumbens. Na Tabela 1 estão apresentados os parâmetros das equações de regressão obtidas pela aplicação dos modelos de Mitscherlich e linear.

A análise da Figura 2 mostra que as plantas dos tratamentos com amicarbazone e diuron apresentaram resposta semelhante do consumo de água da testemunha, com valores inferiores. Para ambos os herbicidas houve 


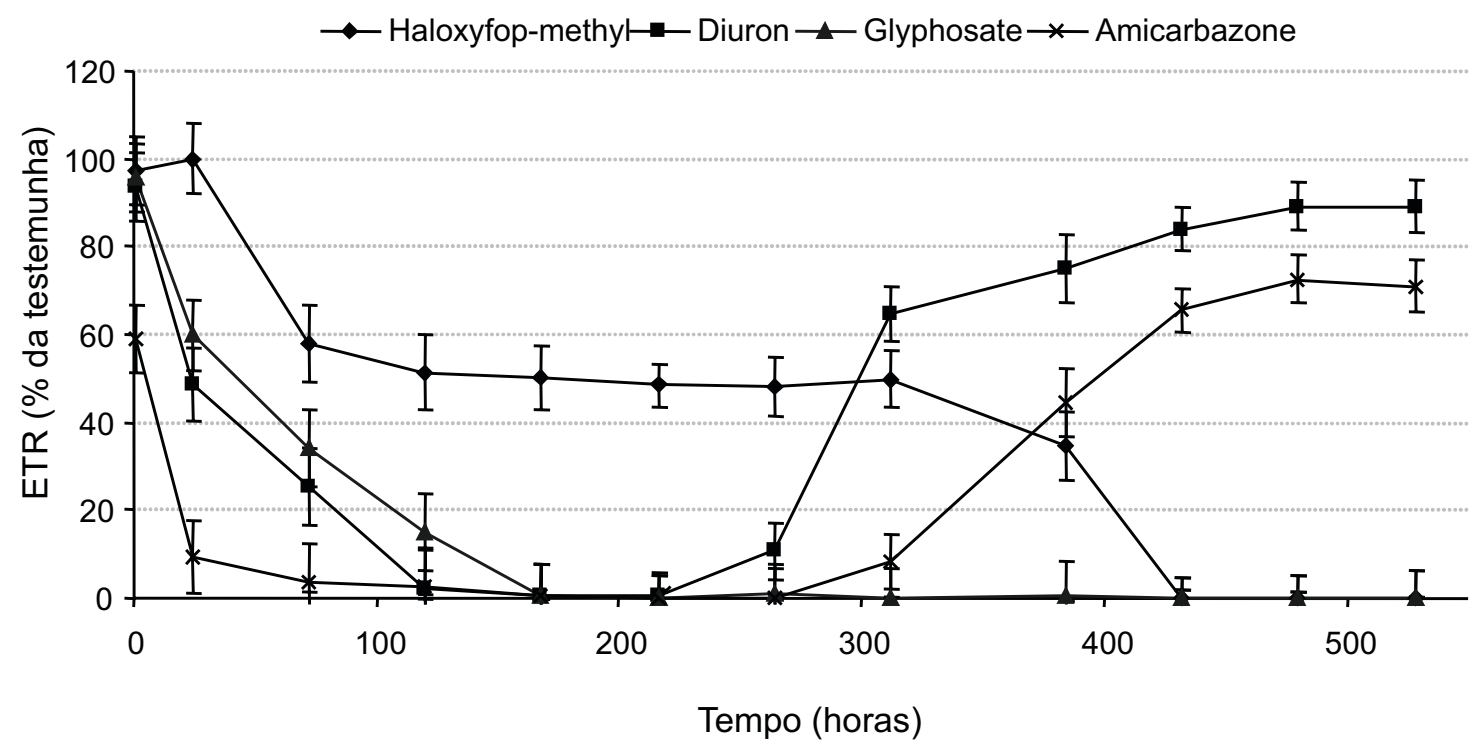

Figura 1 - Comportamento da taxa de transporte de elétrons (ETR) em relação ao tempo, em horas, para as plantas de $B$. decumbens após aplicação de haloxyfop-methyl, glyphosate, diuron e amicarbazone. As barras indicam a DMS dos períodos avaliados. Botucatu-SP-2011.

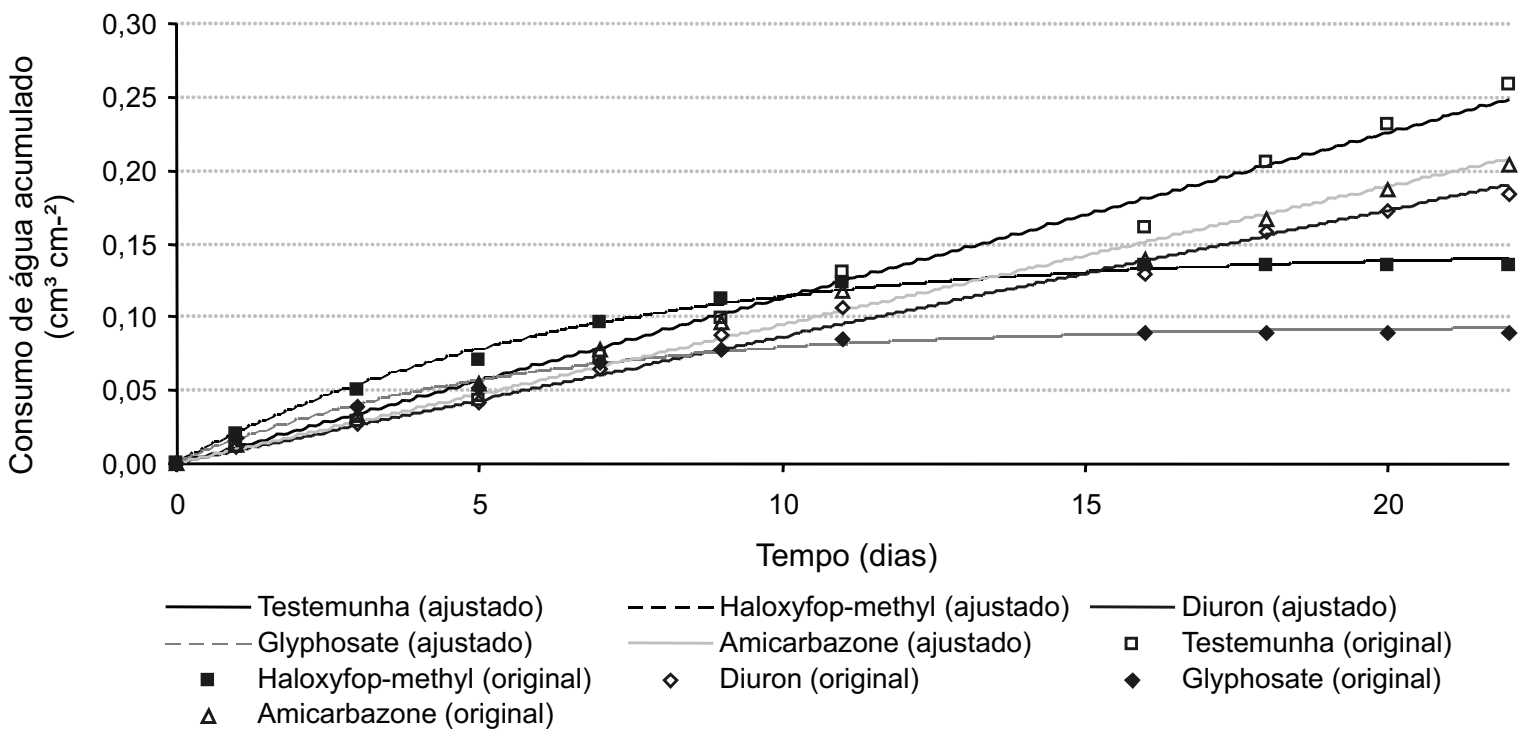

Figura 2 - Comportamento do consumo de água acumulado da planta daninha $B$. decumbens em relação ao tempo, em dias, após a aplicação dos herbicidas haloxyfop-methyl, glyphosate, diuron e amicarbazone. Os dados foram ajustados com o uso dos modelos de Mitscherlich e linear. Botucatu-SP-2011.

menor consumo de água durante o período em que as plantas estavam com o ETR inibido e/ou reduzido, mas esse consumo foi retomado posteriormente, com a recuperação do transporte de elétrons da fotossíntese.

O consumo de água das plantas em que se aplicou o haloxyfop-methyl foi elevado no início, com valores de consumo superiores aos observados na testemunha, porém o consumo de água pelas plantas cessou 264 horas após a aplicação. Nesse período, o transporte de elétrons nas plantas estava bastante reduzido.

Quanto às plantas tratadas com glyphosate, o consumo de água foi normal até o período de 
Tabela 1 - Parâmetros das equações de regressão obtidas pela aplicação do modelo de Mitscherlich para consumo de água acumulado nos diferentes períodos de avaliação, para glyphosate e haloxyfop-methyl, e do modelo linear, para testemunha, amicarbazone e diuron. Botucatu-SP-2011

\begin{tabular}{|l|c|c|c|c|c|}
\hline \multirow{2}{*}{ Herbicida } & \multirow{2}{*}{$\mathrm{R}^{2}$} & \multicolumn{2}{|c|}{ Parâmetro dos modelos } & \multirow{2}{*}{ Valor F } \\
\cline { 3 - 5 } & & $\mathrm{a}$ & $\mathrm{b}$ & $\mathrm{c}$ & \\
\hline Testemunha & 0,9900 & 0,0113 & - & - & - \\
\hline Glyphosate & 0,9957 & 0,0930 & 0 & 0,0804 & $2.089,14$ \\
\hline Haloxyfop-methyl & 0,9937 & 0,1441 & 0 & 0,0668 & $1.420,23$ \\
\hline Amicarbazone & 0,9849 & 0,0094 & - & - & - \\
\hline Diuron & 0,9911 & 0,0086 & - & - & - \\
\hline
\end{tabular}

Significativo a $1 \%$ de probabilidade pelo teste $\mathrm{F}$.

264 horas após a aplicação, visto que posteriormente esse consumo foi interrompido nas plantas. O transporte de elétrons já havia sido interrompido anteriormente a essa inibição do consumo de água nas plantas tratadas com glyphosate.

Na Figura 3, que representa a porcentagem de controle para $B$. decumbens após aplicação dos tratamentos, observa-se que os tratamentos com glyphosate e amicarbazone apresentavam maior porcentagem de fitointoxicação aos sete dias após a aplicação (DAA). Esses tratamentos mantiveram a maior porcentagem de fitointoxicação, com 90 e 95\% de controle aos 14 DAA, respectivamente. Em um ensaio realizado por Tuffi Santos et al. (2005) com aplicação de glyphosate em $B$. decumbens sob condição de solução nutritiva, também se observou alto controle de $95 \%$ das plantas aos 15 dias após a aplicação; as plantas apresentaram raízes com coloração amarronzada, indicando a necrose de tecidos.

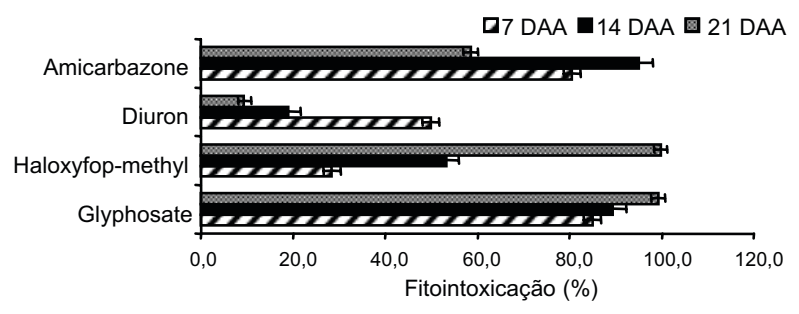

Figura 3 - Porcentagem de fitointoxicação para as plantas de B. decumbens aos 7, 14 e 21 dias após aplicação (DAA) de haloxyfop-methyl, glyphosate, diuron e amicarbazone. As barras indicam a DMS dos períodos avaliados. BotucatuSP-2011
O nível máximo de $100 \%$ de controle foi alcançado aos 21 DAA apenas para as plantas submetidas ao glyphosate e haloxyfop-methyl, visto que aquelas tratadas com amicarbazone e diuron recuperaram-se dos efeitos fitotóxicos proporcionados pelos herbicidas; essa melhora foi verificada na resposta das plantas através da porcentagem de controle, assim como pelos valores de ETR e consumo de água.

Assim, pode-se dizer que as plantas de $B$. decumbens tiveram respostas diferentes aos herbicidas aplicados, e o consumo de água das plantas está relacionado diretamente com o transporte de elétrons. A metodologia fundamentada no fluorômetro mostrou-se adequada para verificar o momento da ação de herbicidas de diferentes mecanismos de ação nas plantas, por meio da verificação instantânea do transporte de elétrons. Para as plantas de $B$. decumbens tratadas com os herbicidas amicarbazone e diuron, é possivel verificar essa intoxicação antecipada através do fluorômetro antes mesmo da verificação visual de intoxicação.

\section{LITERATURA CITADA}

ABBASPOOR, M.; TEICHER H. B.; STREIBIG J. C. The effect of root-absorbed PSI inhibitors on Kautsky curve parameters in sugar beet. Weed Res., v. 46, n. 3, p. 226-235, 2006.

ALVIM, J. M. et al. Métodos de estabelecimento de Brachiaria decumbens em associação com a cultura do milho. R. Bras. Zootec., v. 18, n. 5, p. 417-425, 1989.

BREITENBACH, J.; ZHU, C.; SANDMAN, G. Bleaching herbicide norflurazon inhibits phytoene desaturase by competition with the cofactors. J. Agric. Food Chem., v. 49, n. 11, p. 5270-5272, 2001.

BRODRIBB, T. J.; HOLBROOK, N. M. Stomatal closure during leaf dehydration, correlation with other leaf physiological traits. Plant Physiol., v. 132, n. 4, p. 2166$2173,2003$.

COLE, D. J.; CASELEY, J. C.; DODGE, A. D. Influence of glyphosate on selected plant process. Weed Res., v. 23, n. 3, p. 173-183, 1983.

DAYAN, F. E.; TRINDADE, M. L. B.; VELINI, E. D. Amicarbazone, a new photosystem II inhibitor. Weed Sci., v. 57, n. 6 , p. $579-583,2009$. 
FUERST, E. P.; NORMAN, M. A. Interactions of herbicides with photosynthetic electron transport. Weed Sci., v. 39, n. 3, p. 458-464, 1991.

GENTY, B.; BRIANTAIS, J. M.; BAKER, N. R. The relationship between the quantum yield of photosynthetic electron-transport and quenching of chlorophyll fluorescence Biochim. Biophys. Acta, v. 990, n. 1, p. 87-92, 1989.

IRELAND, C. R.; PERCIVAL, M. P.; BAKER, N. R Modification of the induction of photosynthesis in wheat by glyphosate, an inhibitor of amino acid metabolism. J. Exper. Bot., v. 37, n. 176, p. 299-308, 1986.

KORRES, N. E.; FROUD-WILLIAMS, R. J.; MOSS, S. R. Chlorophyll fluorescence technique as a rapid diagnostic test of the effects of the photosynthetic inhibitor chlortoluron on two winter wheat cultivars. Ann. Appl. Biol., v. 143, p. $53-56,2003$

KRAUSE, G. H.; WINTER, K. Photoinhibition of photosynthesis in plants growing in natural tropical forest gaps: a chlorophyll fluorescence study. Bot. Acta, v. 109, n. 6 , p. 456-462, 1996.

KUVA, M. A. et al. Períodos de interferência das plantas daninhas na cultura da cana-de-açúcar. I -Tiririca.

Planta Daninha, v. 18, n. 2, p. 241-251, 2000
LAISK, A.; LORETO, F. Determining photosynthetic parameters from leaf $\mathrm{CO}_{2}$ exchange and chlorophyll fluorescence. Ribulose-1,5-bisphosphate carboxylase/ oxygenase specificity factor, dark respiration in the light, excitation distribution between photosystems, alternative electron transport rate, and mesophyll diffusion resistance. Plant Physiol., v. 110, n. 3, p. 903-912, 1996.

MAXWELL, K.; JOHNSON, G. N. Chlorophyll fluorescence: a practical guide. J. Exper. Bot., v. 51, n. 345 , p. 659-668, 2000.

STEPHENSON, G. R. et al. Glossary of terms relating to pesticides (IUPAC Recommendations 2006). Pure Appl. Chem., v. 78, n. 11, p. 2075-2154, 2006.

TOLEDO, R. E. B. et al. Faixas de controle de plantas daninhas e seus reflexos no crescimento de plantas de eucalipto. Sci. For., v. 64, n. 1, p. 78-92, 2003.

TUFFI SANTOS, L. D. et al. Exsudação radicular do glyphosate por Brachiaria decumbens e seus efeitos em plantas de eucalipto e na respiração microbiana do solo. Planta Daninha, v. 23, n. 1, p. 143-152, 2005.

YOUNG, A. L.; FRANK, H. A. Energy transfer reactions involving carotenoids: quenching of chlorophyll fluorescence. $\mathbf{J}$. Photochem. Photobiol. B: Biol., v. 36, n. 1, p. 3-15, 1996 